\title{
Protective effect of Moringa peregrina seed oil against doxorubicin-induced hepatotoxicity in male mice
}

\author{
Abdallah M. Sliai ${ }^{{ }^{*}}$ and Gamal H. Abdel-Rahman ${ }^{2}$ \\ ${ }^{1 / 2}$ Department of Biology, Faculty of Science, Taif University, Taif, KSA \\ ${ }^{1}$ Department of Zoology, Faculty of Science, Assiut University, Assiut, Egypt
}

\section{Article history}

Received: 27 Feb, 2016

Revised: 1 Apr, 2016

Accepted: 3 Apr, 2016

\begin{abstract}
The present study aimed to illustrate the histopathological and immunohistochemical changes in the liver of mice exposed to anticancer drug, doxorubicin (DOX), and to evaluate the possible protective role of Moringa peregrina seed oil. Thirty two mature male mice were randomly divided into four groups. One group served as a control, the other was given a dose of $M$. peregrine at the rate of $150 \mathrm{mg} / \mathrm{kg}$ body weight, third group was DOX treated, and fourth was DOX plus M. peregrina treated. Histopathological examination of liver sections showed that DOX caused disturbance in hepatic cords, hepatocytes degeneration, inflammation, necrotic areas, vacuolation and dilation of the blood sinusoids. Doxorubicin treated animals demonstrated a positive reaction to Caspase-3 in hepatocytes as compared with controls. Administration of $M$. peregrina seed oil plus doxorubicin showed reduction in caspase-3 immunoreactivity and apoptotic index induced by DOX. Treatment with M. peregrina seed oil 150 $\mathrm{mg} / \mathrm{kg}$ body weight reduced the damage caused by DOX in the liver.

Keywords: Doxorubicin; Moringa seed oil; histopathology; liver; mice
\end{abstract}

To cite this article: Sliai AM and GH Abdel-Rahman, 2016. Protective effect of Moringa peregrina seed oil against doxorubicin-induced hepatotoxicity in male mice. Res. Opin. Anim. Vet. Sci., 6(2): 69-73.

\section{Introduction}

Cancer is one of the leading causes of death in the world. Doxorubicin (DOX) an anthracycline antibiotic, is one of the most widely used anti-cancer drugs. The toxic side effects of most anti-cancer drugs can damage such organs and systems as the immune system, liver and heart (Saad et al., 2001; Khouri, 2012; Tacar, 2013). Doxorubicin cytotoxic effects have been associated with generation of free radical species such as hydrogen peroxide $\left(\mathrm{H}_{2} \mathrm{O}_{2}\right)$ and hydroxyl radical $(\mathrm{OH})$ during drug metabolism which can cause tissue injury (Mohamad et al., 2009). Several studies reported that there are toxic side effects of the drug on heart as well as other organs including the liver, brain and kidney (Fornari et al., 1994; Carvalho et al., 2009). Doxorubicin hepatotoxicity has been reported in a number of animal studies (Ray et al., 2000 \& 2004; Saad et al., 2001). The liver has a central role in drug metabolism, converting drugs into products that are more easily excreted.

Natural products are valued for their ability to protect against all types of diseases, drugs and chemically induced injuries (Ray et al., 2004). Several natural and synthetic antioxidants have been suggested to protect against DOX-derived cardiotoxicity (Asensio-Lopez et al., 2012; El-Bakly et al., 2012).

Moringa species (Family, Moringaceae) are commonly known as drumstick or horseradish trees. It is indigenous to Northwest India, but at present, it is

*Corresponding author: Abdallah M. Sliai, Department of Zoology, Faculty of Science, Assiut University, Assiut, Egypt 
widely distributed in the tropics throughout the Pacific, West Africa, as well as Central America (Jaiswal et al., 2009). Moringa peregrina occurs in the countries bordering the Red Sea. The leaves, fruits, flowers and immature pods of this tree are used as a highly nutritive vegetable in many countries, particularly in India, Pakistan, Philippines, Hawaii and many parts of Africa (Anwar et al., 2007). Various parts of Moringa species have been studied for several pharmacological actions. Almost all the parts of this plant, seed and seed oil have been used for various medicinal purposes, including the treatment of inflammation and infectious diseases, cardiovascular, gastrointestinal, haematological and hepatorenal disorders (Siddhuraju \& Becker, 2003; Anwar et al., 2007). A report described its antifungal, antimicrobial and antiatherosclerotic effects (Biswas et al., 2012). Most of the parts of the plant are used for the traditional treatment of diabetes (Babu and Chaudhuri, 2005), hepatotoxicity, rheumatism, venomous bites and renal disorders (Jaiswal et al., 2009; Verma et al., 2009). An ethanolic extract of the leaves has been reported for its high antioxidant activity in both linoleic acid and peroxidation and have been found to contain high polyunsaturated fatty acid oil lipid contents (Liu et al., 2008).

The present study aimed to investigate the possible adverse pathological effects of DOX and the protective role of Moringa peregrina seed oil in alleviation of the toxic effects of DOX in the liver of mice.

\section{Materials and Methods}

\section{Animals and experimental design}

Thirty two mature male mice weighing $35 \pm 5 \mathrm{~g}$ were used in the present study. Animals were placed in cages at room temperature in which a $12 \mathrm{~h}$ light cycle was maintained and left to acclimatize for 1 week before the start of the experiment. A standard diet and tap water were provided to animals ad libitum.

Animals were divided into four groups, eight in each group:

Group I (control): Received saline for 14 days orally. Group II: Received orally a single dose of $M$. peregrina seed oil ( $150 \mathrm{mg} / \mathrm{kg} \mathrm{b.w)}$ for 14 days by gavage.

Group III: Animals were injected intraperitoneally with seven doses of DOX ( $2.5 \mathrm{mg} / \mathrm{kg}$ body weight/day), on alternative days for a period of 14 days.

Group IV: Animals were injected intraperitoneally with DOX $(2.5 \mathrm{mg} / \mathrm{kg} / \mathrm{day}$ for each dose $)$ and $M$. peregrina seed oil $(150 \mathrm{mg} / \mathrm{kg}$ body weight $) 1$ hour before DOX dose on alternative day for a period of 14 days.

\section{Histopathological examinations}

At the end of the experiment, animals from each group were killed by cervical dislocation. Liver from animals was carefully separated and cut into small pieces. Samples were placed in $10 \%$ buffered formalin solution for tissue fixation. Samples were dehydrated in ascending grades of ethanol, cleared in xylene and embedded in paraffin. Sections ( $5 \mu \mathrm{m}$ thick) were cut, stained with hematoxylin and eosin (Humason, 1972) and observed under microscope (Leica system, Germany). Randomly five views were recorded per slide in each group.

\section{Immunohistochemistry}

For the detection of caspase-3 protein, immunehistochemical staining was performed. Slides were deparaffinized, dehydrated, washed in phosphate buffer saline, then covered with peroxide block staining and incubated at room temperature in a humid chamber for $10 \mathrm{~min}$. Monoclonal caspase-3 antibody was applied to the tissue sections, then incubated horizontally in a humidity chamber for an hour, at room temperature. After removal of excess buffer, the sections were incubated in preformed strept avidin peroxidase. DAB substrate-chromogen (3.3-Diaminobenzidine tetrahydrochloride) was applied on slides for 5-15 min until the desired brown colour was obtained. Five sections per slide per group were counterstained Mayer's hematoxylin (Sternberger, 1986).

\section{Results}

\section{Histopathological examination:}

Light microscopic examination of liver sections of control and M. peregrina treated animals revealed that the hepatic lobules appeared to be formed of hepatocytes arranged in cords radiating from the central veins. The hepatic sinusoids were seen as narrow spaces in between the hepatic cords. The hepatocytes with well-preserved cytoplasm and visible rounded nuclei with fine arrangement of Kupffer cells (Figs. $1 \mathrm{~A} \& \mathrm{~B})$.

In contrast, animals receiving DOX revealed obvious changes relative to control animals. The most obvious pathological abnormalities include disturbance of hepatic cords. Many of the hepatocytes were destroyed, forming degeneration areas. There were increasing numbers of inflammatory cells and necrotic hepatocytes. The blood sinusoids were dilated and some of the hepatocytes showed cytoplasmic vacuoles with degenerated nuclei (Figs. 1C\&D).

\section{Immunohistochemical observations}

Expression of hepatic tissue caspase-3 (apoptotic index)

Apoptotic immunopositive reactions in the liver were investigated with caspase- 3 . In control and $M$. peregrina treated animals, there was a weak reaction of caspase-3 with hepatocytes (Fig. 2A \& B). The expression of caspase- 3 was more positive with hepatocytes in case of 

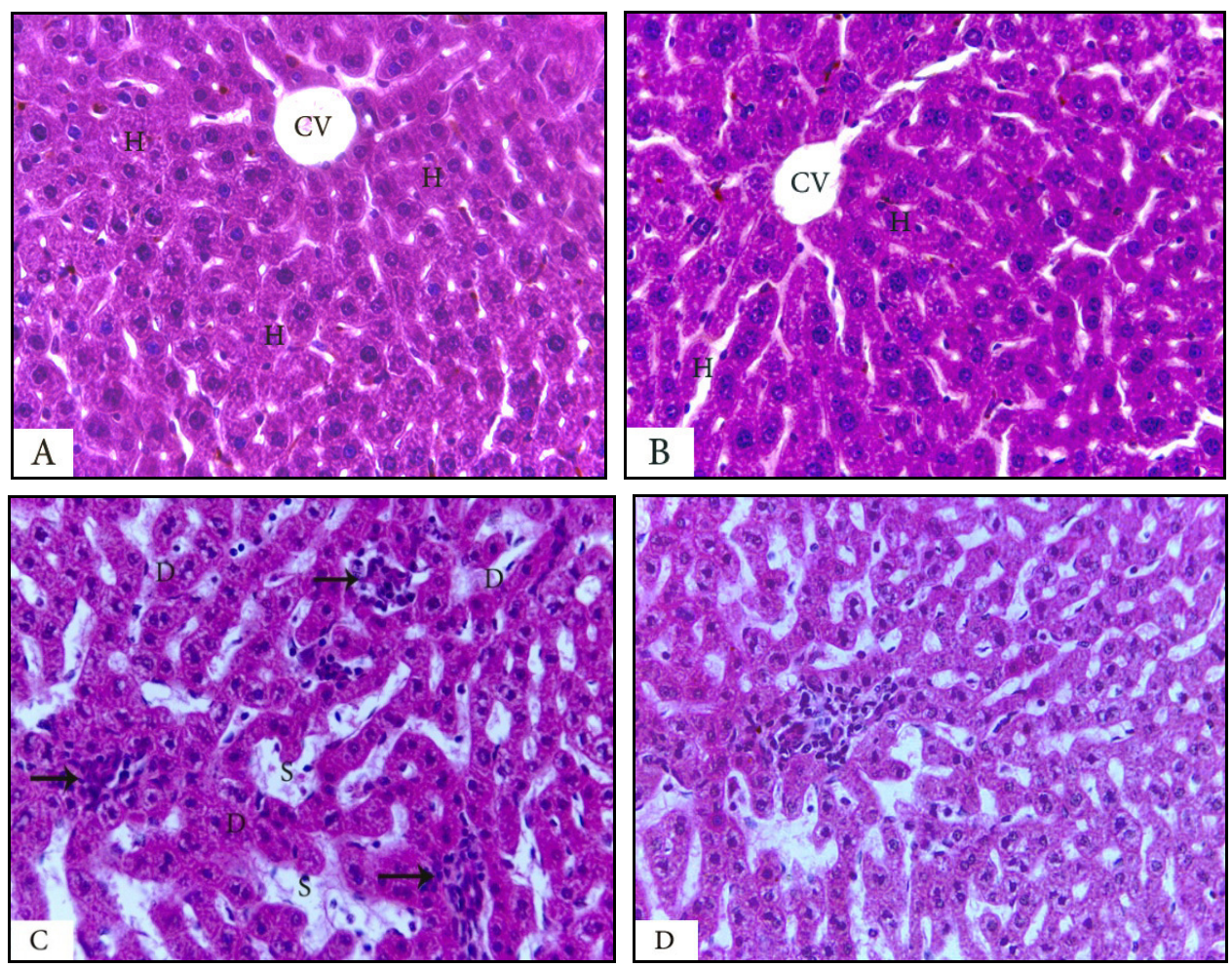

Fig. 1: Hematoxylin and eosin staining of liver in control (A), Moringa (B), showing normal liver structure, central vein (CV) and hepatocytes (H). DOX treated animals (C) showing disturbance of hepatic cords, hepatocytes degeneration (D), inflammatory infiltration (arrows), swallow sinusoids (S) and necrosis. DOX plus Moringa (D) illustrating slight improvement of pathological changes (H\&E, X400).
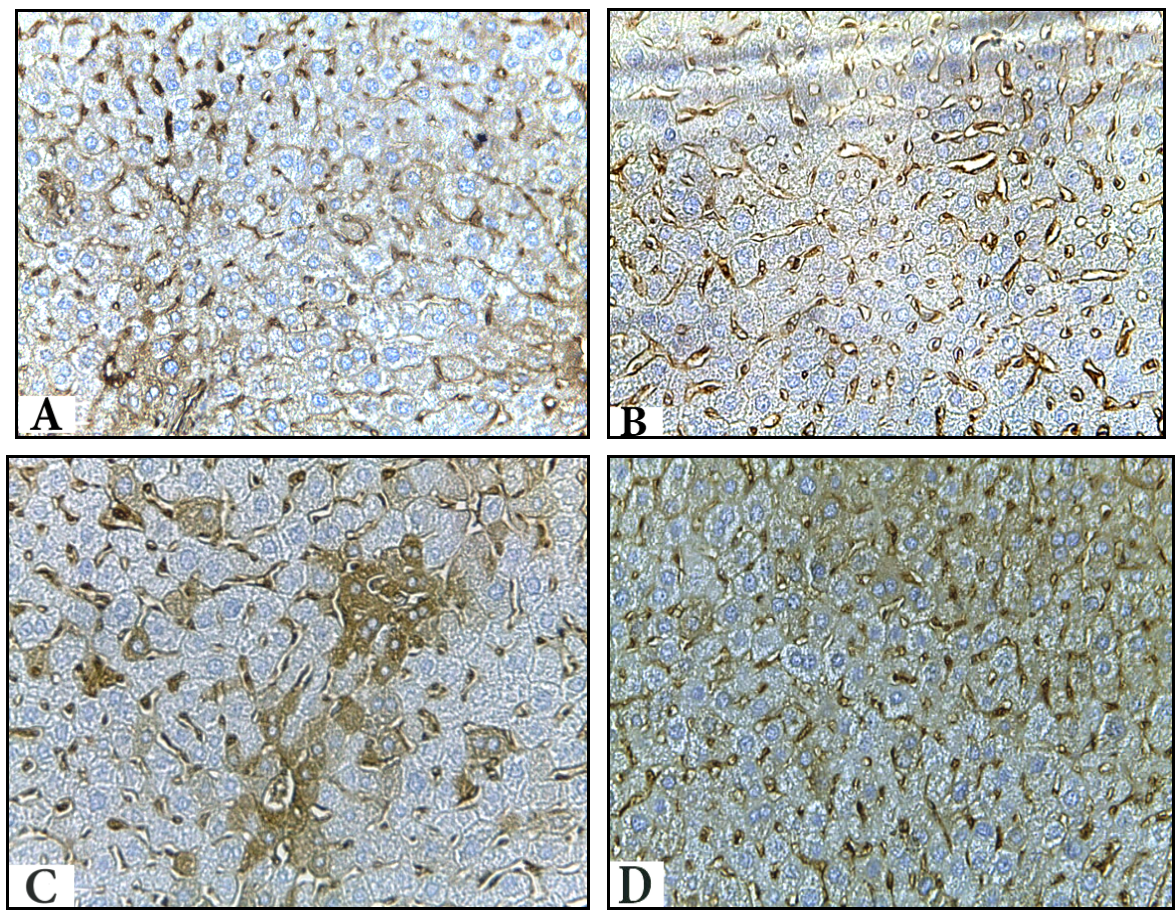

Fig. 2: Photomicrographs of sections of the liver with caspase-3 immunoreactivity, A\&B: control and M. peregrina seed oil treated mice showing negative reaction, $\mathrm{C}$ : doxorubicin treated group showing positive immunoreaction of hepatocytes for caspase- 3, D: doxorubicin plus wheat $M$. peregrina seed oil showing moderate immunoreaction (X 400) 
Res. Opin. Anim. Vet. Sci., 2016, 6(2): 69-73.

Table 2: Semi-quantitative analysis of caspase-3 immunostaining density in the liver

\begin{tabular}{ccccc}
\hline & Control & Moringa & Doxorubicin & Doxorubicin \& Moringa \\
\hline$($ Caspase-3) & + & + & +++ & ++ \\
\hline
\end{tabular}

Caspase- 3 reactivity was estimated as follows: weak: + , moderate: ++ , strong $:+++$.

DOX treated animals as compared with controls (Fig. 2C). Doxorubicin plus $M$. peregrina treated animals showed less reaction to Caspase-3 immunoreactivity (Fig. 2D).

\section{Discussion}

The present study was designed to evaluate pretreatment with $M$. peregrina seed oil, which would have a hepatoprotective effect on doxorubicin induced liver damage as a side effect. The liver is the main site of DOX metabolism. Many studies suggested that oxidative stress plays an important role in DOXinduced damage of normal cells or tissues Saad et al., 2001; Agapito et al., 2001; Kolarovic et al., 2010). Inflammation is a major component in the pathogenesis of DOX toxicity that is orchestrated in part by endogenous and migrating leukocytes. Abd El-Aziz et al. (2001) demonstrated that a $15 \mathrm{mg} / \mathrm{kg}$ single injection of DOX caused increased lipid peroxidation and produced reactive oxygen species in liver tissue, thus reduced the antioxidant defence mechanism. Dilatation of the blood sinusoids and degeneration may be due to this stress. Side-effects of the DOX in this study revealed histopathological structural changes in the liver. These changes include a marked disruption of hepatic cords, hepatocytes degeneration, dilated blood sinusoids, inflammatory infiltration and necrosis. Pathological changes in this study due to exposure to DOX are in agreements with previous reports in rats (Saad, et al., 2001; Kalender and Kalender, 2005; ElSayyad et al., 2009). Apoptosis is an important mechanism regulating cell number and their development in different organs and tissues and is a common feature of hepatotoxicity induced by chemicals or drugs. Doxorubicin is known to kill cells primarily by fragmenting DNA and causing cell death by apoptosis (Ray and Jena, 2000; Patel et al., 2010). In the present study, immunohistochemistry for caspase-3 expression in mice livers indicated that DOX induced apoptosis in hepatocytes. In this study, the number of apoptotic cells was increased in the liver of the DOX group in comparison with the control. This is in accordance with Abdel-Rahman and Abdel-Hady (2013) who stated that anticancer drugs, cisplatin cause apoptosis in tissues. Natural products including plants, provide rich resources for anticancer drug discovery (Schwartzmann et al., 2002). Moringa species are one of the most useful tropical trees with a multiple of uses. They are widely cultivated among the species of family Moringacae. Leaves of Moringa species have a good source of natural antioxidants due to the presence of various compounds as ascorbic acid, flavenoids, phenolic compounds and carotenoids (Pari et al., 2007). Many studies reported that the plant has antiinflammatory antitumour activity and used for treating diabetes, inflammation, cardiovascular diseases, liver diseases, haematological, hepatic and renal functions (Ezeamuzle et al., 1996; Murakami et al., 1998). The above results are in agreements with this study in which $M$. peregrina seed oil decreased the pathological changes compared with the DOX group. In this study also, apoptotic index was increased in hepatocytes of DOX treated animals, while a slight reduction in hepatocytes of DOX treated plus M. peregrina seeds oil treated animals was observed.

\section{Conclusion}

The present study revealed that side effects of DOX include several pathological changes in liver and apoptosis. Treatment with M. peregrina seed oil 150 $\mathrm{mg} / \mathrm{kg}$ body weight reduced the damage caused by DOX in the liver.

\section{References}

Abd El-aziz M, Othman A, Amer M, El-Missiry MA (2001) Potential protective role of angiotensinconverting enzyme inhibitors captopril and enalapril against adriamycin-induced acute cardiac and hepatic toxicity in rats. J Appl Toxicol 21: 469-473.

Abdel-Rahman GH, Abdel-Hady EK (2013) Silymarin ameliorates cisplatin-induced hepatotoxicity in male rabbits. Life Science Journal 10(1):33333341.

Agapito MT, Antolín Y, del Brio MT, López-Burillo S, Pablos MI, Recio JM (2001) Protective effect of melatonin against adriamycin toxicity in the rat. $\mathrm{J}$ Pineal Res 31(1):23-30.

Anwar F, Latif S, Ashraf M, Gilani AH (2007) Moringa oleifera: A food plant with multiple medicinal uses. Phytother Res 21: 17-25.

Asensio-Lopez, MC, Sanchez-Mas J, Pascual-Figal DA, Abenza S, Perez-Marti- nez, MT, Valdes M, Lax A (2012) Involvement of ferritin heavy chain in the preventive effect of metformin against doxorubicin-induced cardiotoxicity. Free Rad Biol Med 57: 188-200.

Biswas SK, ChowdhuryA, Das J, Roy A, Zahid SM (2012) Pharmacological potentials of moringa 
oleifera Lam.: a review. Int J Pharm Sci Res 3(2): 305-310.

Babu R, Chaudhuri M (2005) Home water treatment by direct filtration with natural coagulant. J Water Health 3: 27-30.

Carvalho RX, Santos S, Cardoso S, Correia PJ, Oliveira MS Santos PI Moreira (2009) Doxorubicin: the good, the bad and the ugly effect. Curr Med Chem 16: 3267-3285.

El-Bakly WM, Louka ML, El-Halawany AM, Schaalan MF (2012) 6-gingerol ameliorated doxorubicininduced cardiotoxicity: role of nuclear factor kappa $\mathrm{B}$ and protein glycation. Cancer Chemother Pharmacol 70: 833-841.

El-Sayyad HI, Ismail MF, Shalaby FM, Abou-El-Magd RF, Gaur RL, Fernando A, Raj MH, Ouhtit A (2009) Histopathological effects of cisplatin, doxorubicin and 5-flurouracil (5-FU) on the liver of male albino rats. Int J Biol Sci 5: 466-73

Ezeamuzle IC, Ambedederomo AW, Shode FO, Ekwebelem SC (1996) Antiinflammatory effects of Moringa oleifera root extract. Int J Pharmacogn 34: 207-212

Fornari FA, Randolph JK, Yalowich JC, Ritke MK, Gewirtz DA (1994) Interference by doxorubicin with DNA unwinding in MCF-7 breast tumor cells. Mol Pharmacol 45: 649-656.

Humason GL (1972) Animal tissue techniques. $3^{\text {rd }}$ edn. WH Freeman and Company San Francisco. PP: 180-182.

Jaiswal D, Rai PK, Kumar A, Mehta S, Watal G (2009) Effect of Moringa oleifera Lam. leaves aqueous extract therapy on hyperglycemic rats. J Ethnopharmacol 123: 392-6.

Kalender Y, Yel M, Kalender S (2005) Doxorubicin hepatotoxicity and hepatic free radical metabolism in rats. The effects of vitamin $\mathrm{E}$ and catechin Toxicology209:39e45.

Kolarovic J, Popovic M, Zlinská J, Trivic S, Vojnovic M (2010) Antioxidant activities of celery and parsley juices in rats treated with doxorubicin. Molecules 15: 6193-6204.

Liu X, Zhao M, Wang J, Yang B, Jiang Y (2008) Antioxidant activity of methanolic extract of emblica fruit (Phyllanthus emblica L.) from six regions in China. J Food Compos Anal 21: 219-228.

Khouri MG, Douglas PS, Mackey JR Martin M, Scott M, Scherrer-Crosbie M, Jones LW (2012) Cancer therapy-induced cardiac toxicity in early breast cancer: addressing the unresolved issues. Circulation 126: 2749-2763.

Mohamad RH, El-Bastawesy AM, Zekry ZK, AlMehdar HA, Al-Said MG, Aly SS, Sharawy SM, El-Merzabani MM (2009). The role of Curcuma longa against doxorubicin (adriamycin)-induced toxicity in rats. J Med Food 12(2): 394-402.

Murakami A, Kitazonz Y, Jiwajinda S, Koshimizu K , Ohigashi H (1998) Niaziminin, a thio carbamate from the leaves of Moringa oleifera, holds a strict structural requirement for inhibition of tumor promotor-induced Epstein-Barr virus activation. Planta Med 64: 319-323.

Pari L, Kuramac M, Kosinska A, Rybarczyk A (2007) Antioxidant activity of the crude extracts of drumstick tree (Moringa oleifera Lam ) and sweet bromweed (scoparia dulcis L.) leaves. Pol J Food Nutr Sci 57: 203-208.

Patel N, Joseph C, Corcoran GB, Ray SD (2010) Silymarin modulates doxorubicin-induced oxidative stress, Bcl-xL and p53 expression while preventing apoptotic and necrotic cell death in the liver. Toxicol Appl Pharmacol 245(2): 143-52.

Ray SD, Balasubramanian G, Raje R, Reid VE, Reddy CS, Bagchi D (2000) Doxorubicin-induced hepatotoxicity may involve apoptotic cell death by modulating expression of Bcl-xL and p53. Toxicol Scs 4: 100.

Ray SD, Lam TS, Rotollo JA, Rotollo JA, Phadke S, Patel $C$ et al. (2004) Oxidative stress is the master operator of drug and chemically-induced programmed and unprogrammed cell death: implications of natural antioxidants in vivo. Biofactors 21: 223-232.

Saad SY, Najja TA, Al-Rikabi AC (2001) The preventive role of deferoxamine against acute doxorubicin induced cardiac, renal and hepatic toxicity in rats. Pharmacol Res 43: 211-8.

Schwartzmann G, Ratain MJ, Cragg GM, Wong JE, Saijo N, Parkinson D, Fujiwara Y, Pazdur R, Newman DJ, Dagher R, Di Leone L (2002) Anticancer drug discovery and development throughout the world. J Clin Oncol 20: 47S-59S.

Siddhuraju P, Becker K (2003) Antioxidant properties of various solvents extracts of total phenolic constituents from three different agroclimatic origins of drumstick tree (Moringa oleifera) leaves. J Agri Food Chem 51: 2144-2155.

Sternberger LA (1986) Immunocytochemistry. $3^{\text {rd }}$, Edn. John Wiley Medical, New York, ISBN10:0471867217: 524.

Tacar O, Sriamornsak P, Dass CR (2013) Doxorubicin: an update on anticancer molecular action, toxicity and novel drug delivery systems. J Pharm Pharmacol 65: 157-170.

Verma AR, Vijayakumar M, Mathela CS, Rao CV (2009) In vitro and in vivo antioxidant properties of different fractions of Moringa oleifera leaves. Food Chem Toxicol 47: 2196-201. 